\title{
Hydrological Cycle and Lake Water Source Indicated by Microrelief-Evaporite-Vegetation-Runoff Assemblage of Badain Jaran Desert
}

\author{
Yandong Ma ${ }^{1,2,3}$, Jingbo Zhao ${ }^{2,4, *}$, Tianjie Shao ${ }^{4}$, Zhifeng Jia ${ }^{1,3, * \mathbb{C}}$, Zhiqiang Zhao ${ }^{1,3}$ and \\ Zilong Guan 1,3 \\ 1 School of Environmental Science and Engineering, Chang'an University, Xi'an 710054, China \\ 2 State Key Laboratory of Loess and Quaternary Geology, Institute of Earth Environment, Chinese Academy \\ of Sciences, Xi'an 710075, China \\ 3 Key Laboratory of Subsurface Hydrology and Ecological Effects in Arid Region of the Ministry of Education, \\ Chang'an University, Xi' an 710054, China \\ 4 School of Geography and Tourism, Shaanxi Normal University, Xi'an 710062, China \\ * Correspondence: zhaojb@snnu.edu.cn (J.Z.); 409538088@chd.edu.cn (Z.J.)
}

Received: 22 May 2019; Accepted: 27 June 2019; Published: 29 June 2019

check for updates

\begin{abstract}
The hydrologic process of the sandy desert remains a focus in research in arid areas. Three major natural phenomena that can indicate the hydrological cycle in the extremely dry Badain Jaran Desert were found, namely the assemblage of megadune microrelief and evaporite, megadune vegetation and microrelief, as well as lakeside runoff and vegetation. The microrelief sand layer water, evaporite minerals, and lakeside hydrogeological features were analyzed by the drying and weighing method, environmental scanning electron microscopy with energy spectrum analysis functions, and a hydrogeological borehole survey. The water content of the microrelief $0-0.5 \mathrm{~m}$ sand layer is between $4.7 \%$ and $9.3 \%$. The evaporite minerals are mainly composed of calcite $\left(\mathrm{CaCO}_{3}\right)$ and gypsum $\left(\mathrm{CaSO}_{4}\right)$. The shallow groundwater system in the off-shore area of lakes consists of an aeolian sand layer, a peat layer, and a lacustrine sedimentary layer, and the phreatic water with a thickness of $20 \mathrm{~cm}$ to $40 \mathrm{~cm}$ is reserved in the bottom of aeolian sand layer with a peat layer as a waterproof baseboard. Based on these results, the above three natural phenomena can be explained as follows: (1) The assemblage of megadune microrelief and evaporite was caused by the outcropping of water from megadune vadose zone in the form of preferential flow for a long time. Its leading edge differential wind erosion and calcium cemented fine sand layer indicate that water from the megadune vadose zone moves to and recharges the microrelief water along the micro-scale fine sand layer, during which, it features a multiple layer as it is controlled by a vertical dune bedding structure. (2) The small-scale assemblage of megadune vegetation and microrelief indicates that the water from the megadune vadose zone moved laterally and led to vegetation development, and the assemblage of microrelief and vegetation at a slope scale indicates that the vadose zone water presented multilayer enrichment and runoff producing due, to a great extent, to the bedding structures of different spacial locations. (3) The assemblage of lakeside runoff and vegetation is related to the phreatic water recharged by precipitation surrounding the lake, which indicates that the megadune water recharged by precipitation moved to the bottom of the megadune and constituted supply to the lake water. The three assemblages fully demonstrate that the megadune water recharged by precipitation in this desert could recharge the groundwater water and even lake water in the form of preferential flow due to the control of the bedding structure of different scales within the megadune. The results of lake water balance and the occurrence conditions of phreatic water surrounding the lake imply that the precipitation in this desert plays an important role in sustaining the lake. This study provides reliable evidence for revealing the essence of the hydrological cycle and the source of lake water in the Badain Jaran Desert, which indicates that although precipitation is small, it cannot be ignored in arid sandy desert areas.
\end{abstract}


Keywords: vadose zone water; preferential flow; vegetation pattern; dune bedding structure; phreatic water

\section{Introduction}

The global arid area accounts for about 30\% of the total land area, and sandy deserts are an important geographic unit in the region. Surface water in an arid area is often scarce and extremely unreliable, so the main source of water is groundwater in the area. The Badain Jaran Desert (BJD) in Northwestern China is a typical sandy desert in the global arid area. It has the world's largest number of megadunes and lakes [1-4]. The combination of megadunes and lakes constitutes a unique natural landscape, and this landscape has attracted the attention of relevant researchers, particularly research on the source of lake water [4]. With regard to the recharge source of lake water in the megadune-lake area of BJD, there are four different understandings. First, the lake water in the area comes from the ancient water of late Pleistocene or Holocene $[5,6]$. In view of the strong evaporation in the area, there are also differences on whether or not the residual water of late Pleistocene can be preserved to the present. Second, the lake water comes from the infiltration of atmospheric precipitation $[1,7,8]$. Owing to the low annual precipitation in the area, there is no convincing direct evidence for the view that atmospheric precipitation is the source of lake water. Third, the lake water comes from the precipitation recharge in the Yabrai and Beidashan mountains in the southeastern part of the desert [9-11]. Fourth, the lake water is mainly transported from Qinghai-Tibet Plateau through deep fractures [12-14]. Such a view lacks reliable geological evidence and has contradictions that are difficult to explain, such that it has been challenged by the vast majority of researchers. The lake is mainly controlled by groundwater and evaporation in the desert [9], so the essence of the lake source problem is the groundwater source problem. According to previous research results, the potential recharge source of groundwater in the desert can be roughly divided into namely atmospheric precipitation, residues ancient water, and groundwater outside the desert. So far, the lack of hydrogeological and meteorological data is the root cause of the difficulty in reaching a consensus on the source of groundwater in the megadune-lake area of BJD, and the diversity of interpretations of isotope and water chemistry is exacerbating this divergence. Against a background of ongoing climate change, water scarcity will become an increasingly critical issue in the arid region's future. In addition to the essential problem of the lake development in BJD, the supply source of the groundwater in the desert also affects the rationality of water resources dispatching and management in the Hei River basin in the western part of the desert. Therefore, it is necessary to further carry out research on water circulation and lake water sources in the desert.

In general, atmospheric precipitation is an important source of groundwater in arid region [15-17]. Scanlon et al. [15] comprehensively analyzed the recharge rate of groundwater in the global arid area by summarizing the research results of predecessors. Their results show that the average annual recharge rate of groundwater in an area of $40-374,000 \mathrm{~km}^{2}$ is between $0.2-35 \mathrm{~mm}$, equivalent to $0.1-5 \%$ of the long term average annual precipitation in the region. The precipitation in BJD is only about $100 \mathrm{~mm}$ [18]. Through short-term observation on sand layer water and observation on simulated precipitation infiltration into sand layer, some researchers held that the sand layer water recharged by precipitation of BJD cannot move to and recharge the deep sand layer water or groundwater [14,19] and the water will be completely consumed due to evaporation within a short time after the end of precipitation [20]. On the basis of speculating underground deep fault zone water diversion, Chen et al. [13] speculated that during the upwelling process of underground low-temperature hydrothermal water, the water vapor generated rises along the megadune vadose zone to recharge the sand layer water. Researchers have evaluated the replenishment quantity of precipitation to sand layer water through the methods of physical modeling, water balance, and chloride balance principle, which indicate that the supply rate of precipitation on the Badain Jaran megadune falls between 1-14\% $[1,5,6,10,21]$. Unfortunately, 
these evaluation results are subject to great uncertainty, which can be put down to the lack of observation data of long-term precipitation and sand layer water evaporation leading to a failure in obtaining effective confirmation of many evaluation parameters and the limitation of the application of the chlorine balance method. The spatial and temporal variability of precipitation in sandy desert areas is large and the annual precipitation often depends on some concentrated precipitation days, and the nature of the underlying surface also greatly changes the impact of climate on the regional water cycle and water balance [16,22,23]. Dong et al. [4] summarized this earlier research and proposed that recent precipitation recharge to the lakes must be considered as occurring in the BJD. Therefore, researchers who believe that precipitation cannot replenish sand water are likely to underestimate or ignore the effects of highly concentrated precipitation and complex underlying properties of the BJD on contemporary sandy desert hydrological processes.

During the field survey of BJD, we found three assemblages that have an important indicative function for the water movement of the megadune and lake water source, namely the assemblage of the megadune microrelief and evaporite, megadune vegetation, and microrelief, as well as lakeside runoff and vegetation. Currently, researches on the landform and hydrological cycle of the sandy desert have achieved fruitful results. However, reports on microrelief-evaporite-vegetation-runoff assemblage of the BJD are rarely seen. Based on the three assemblages with indicative significance on hydrology in the BJD, this study reveals the internal link of the desert's natural hydrology phenomena under the current weather condition, so as to further explore the source of megadune water, water movement of the vadose zone, and the desert's lake water source. The BJD is an important part of the world's arid sandy desert. The scale and number of the megadunes and lakes in the desert are incomparable to other sandy deserts in the world. Therefore, this study is not only important for revealing the water cycle and the source of lake water in the BJD, but also has important reference value for understanding the hydrology and water resources of other sandy desert areas in the world.

\section{Materials and Methods}

The BJD is located in the Alxa Right Banner of the Inner Mongolia Autonomous Region (Figure 1a). It is the second largest desert in China, with an area of about $5.2 \times 10^{5} \mathrm{~km}^{2}$, and its megadunes are densely distributed, occupying $61 \%$ of the total desert area [3]. The elevation of BJD is in the range of $1200-1700 \mathrm{~m}$. The height differences in megadunes are mostly in the range of $200-300 \mathrm{~m}$ and the largest height difference is close to $500 \mathrm{~m}$, making them the megadunes with the largest height differences in the world. The number of lakes is about 110 , the largest area is about $2.32 \mathrm{~km}^{2}$, and the deepest is about $16 \mathrm{~m}$. The BJD is characterized by an extreme arid climate in a temperate zone, with scarce precipitation mostly concentrated in the period from June to August [18]. In a normal year, precipitation in the megadune lake area can reach about $100 \mathrm{~mm}$ [18]. The annual average temperature in the area is $7-8{ }^{\circ} \mathrm{C}$, but the maximum temperature in summer can reach $38-43^{\circ} \mathrm{C}$. The annual average wind speed is $4 \mathrm{~m} / \mathrm{s}$, and the number of days with a fresh gale each year totals about 30, mainly north-westerly. The Hei River in the western part of the desert is the closest inland river to the desert. Due to the arid climate and the impact of agricultural irrigation in the upper reaches of the Hei River, there is often a break in the lower reaches of the Hei River. The altitude of the mountains in the south and west of the desert usually does not exceed $2000 \mathrm{~m}$.

A systematic field investigation was carried out around the megadunes to the east of Zhalate Lake (Figure 1a,b) and Yinderitu Lake (Figure 1a,c). On the windward slope of the two megadunes, 9 assemblages of microrelief and evaporite, and 4 assemblages of vegetation and microrelief were surveyed with 5 evaporite samples collected, and 4 microrelief $0-0.5 \mathrm{~m}$ sand layer water content samples collected for the profile analysis. In the offshore area of lake, the assemblage of vegetation and runoff was investigated, and 5 hydrogeological surveys of $5 \mathrm{~m}$ deep small boreholes were initially carried out. The water content analysis sample of the sand layer was collected by a digging section and one sample was taken at intervals of $5 \mathrm{~cm}$. The sample weighed about $40-50 \mathrm{~g}$ and a total of 36 samples were collected. The sand layer water content was determined by a drying and weighing method. 
The sand layer water content sample is needed to determine the initial weight in the collection process. After the sand layer water content sample was taken back to the laboratory, it was placed in a constant temperature blast drying oven at $105^{\circ} \mathrm{C}$ until it was constant weight. After the evaporite samples were collected, they were placed in an aluminum box covered with absorbent cotton and taken back to the laboratory for pretreatment. Sample preparation was carried out via these three steps: (1) The sample was sufficiently dried, (2) interference, such as absorbent cotton fiber and sand, was removed as much as possible from the surface of the sample, and (3) the surface of the sample was uniformly plated with gold. The pre-treated samples were identified by environmental scanning electron microscopy (ESEM) with energy spectrum analysis functions (Quanta 200) to determine the crystal form and chemical components of evaporite. The detection error of the chemical composition analysis was $1 \%$.
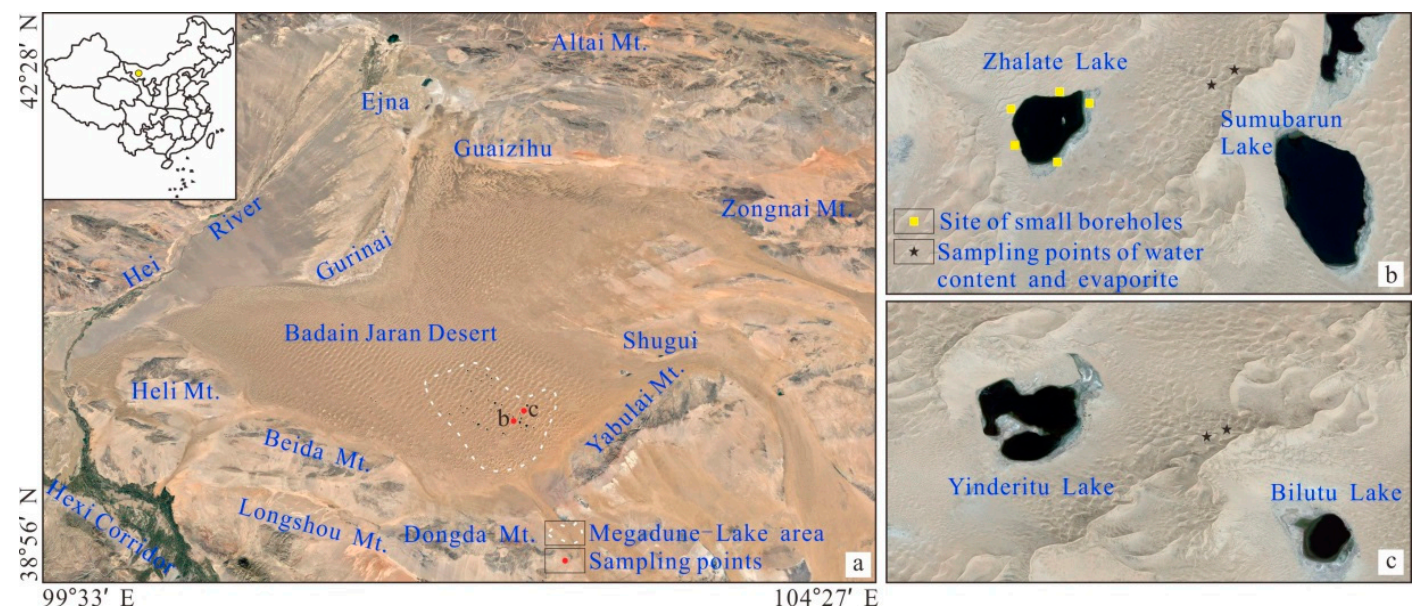

Figure 1. Overview of Badain Jaran Desert (a) and distribution of sampling points (b,c).

\section{Results}

\subsection{Assemblage of Megadune Microrelief and Evaporite}

Microrelief of three basic forms commonly seen in the megadune slope of the BJD includes an arc-shaped microrelief (Figure 2a), a fan-shaped microrelief (Figure 2b), and a tongue-shaped microrelief (Figure 2c). The inclination angle of the megadune slope where the microreliefs are located falls between $15^{\circ}$ and $30^{\circ}$ and these microreliefs are mainly distributed in the middle and upper part of megadune. The arc-shaped microrelief features various scales and its form is hard to be maintained for a long time on megadunes. The fan-shaped microrelief and tongue-shaped microrelief feature on a large scale and their forms can sustain for a long time on megadunes. Part of the tongue-shaped microrelief was sustained for eight years since its discovery and its form continues to be sustained despite the strong impact of wind erosion. A field survey indicates that these microreliefs are composed of arc-shaped steps, but there are differences in the number and density of the arc-shaped steps that make up these microreliefs (Figure 2a-c). In other words, the arc-shaped steps constituting the arc-shaped microrelief feature small quantity and scarce arrangement from top to bottom, and the arc-shaped steps constituting fan-shaped and tongue-shaped microrelief feature large quantity and dense arrangement from bottom to top. The top of arc-shaped steps faces toward the bottom of the slope. The length of arc-shaped steps is usually around $0.5-3 \mathrm{~m}$, sometimes close to $10 \mathrm{~m}$. The inclination angle of the step surface is less than one third of the inclination angle of the megadunes slope. The width of the step surface decreases from top to both sides and its top width roughly ranges from 5 to $20 \mathrm{~cm}$, the height of step scarp also decreases from top to both sides, and its top height roughly varies from 1 to $5 \mathrm{~cm}$ in the arc-shaped steps. Through surveying the internal structure (Figure 2d,e) of the microreliefs, it was found that the internal structure of these microreliefs remains consistent with the original dune strata 
and the development of arc-shaped steps is closely related to the alternating bedding structure of the coarse and fine sand layer of the original dune strata.

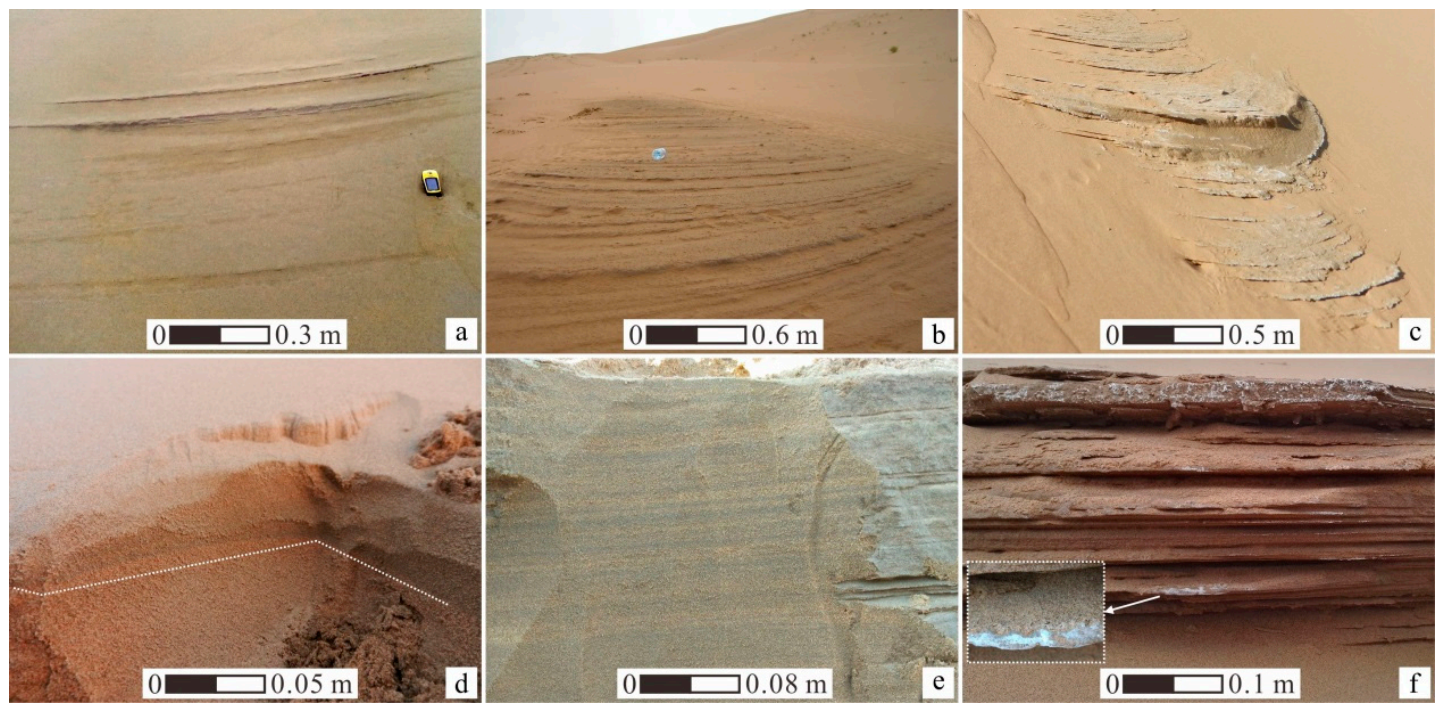

Figure 2. The assemblage of microrelief and evaporite of the Badain Jaran megadune (a-c), the internal structure of microrelief $(\mathbf{d}, \mathbf{e})$, and the differential wind erosion and evaporite at the leading edge of microrelief $(\mathbf{f})$ : $(\mathbf{a}, \mathbf{b}, \mathbf{d})$ is located in the Zhalate megadune; $(\mathbf{c}, \mathbf{e}, \mathbf{f})$ is located in the Yinderitu megadune.

The wet sand layer exposed by wind erosion is a common phenomenon in the megadunes of BJD. It is worth noting that the form of wet sand layer exposed by wind erosion usually is difficult to maintain for a long time due to strong water evaporation and wind blow sand activity. In comparison, the microrelief that we found can not only develop for a long time but can also exhibit different forms on the megadune slope (Figure 2a-c), so the cause of this microrelief cannot be simply attributed to wind erosion. In addition to different forms, the microrelief is also characterized by high water content, which is different from the surrounding aeolian sand. The measurement results (Table 1) of the water content of the microrelief 0-0.5 m sand layer indicate that the water content falls between $4.7 \%$ to $9.3 \%$, which is significantly higher than the water content of $1-3 \%$ of the general aeolian sand layer $[19,24]$. The high moisture content of the sand layer can effectively enhance the sand layer's ability to resist wind erosion. As a result, water is the key factor for the development of microrelief on the megadune slope. The precipitation of the desert is only $100 \mathrm{~mm}$ [18] and the microrelief development location is over $100 \mathrm{~m}$ from the phreatic water level, so the precipitation and groundwater are unlikely to directly cause the microrelief sand layer to maintain a high level of water all year round. However, it is worth considering for precipitation to seep into the megadune and recharge microrelief water in the form of the vadose zone water movement.

Table 1. Water content of microrelief sand layer in the megadune of the Badain Jaran Desert (\%).

\begin{tabular}{cccccccccc}
\hline Depth/cm & $\mathbf{5}$ & $\mathbf{1 0}$ & $\mathbf{1 5}$ & $\mathbf{2 0}$ & $\mathbf{2 5}$ & $\mathbf{3 0}$ & $\mathbf{3 5}$ & $\mathbf{4 0}$ & $\mathbf{4 5}$ \\
\hline Zhalate profile 1 & 9.3 & 8.7 & 8.4 & 8.5 & 8.1 & 7.3 & 7.6 & 6.9 & 6.2 \\
Zhalate profile 2 & 7.9 & 8.4 & 7.6 & 6.3 & 7.2 & 5.8 & 6.7 & 4.8 & 5.0 \\
Yinderitu profile 3 & 8.3 & 8.7 & 7.0 & 7.6 & 5.7 & 6.8 & 6.5 & 5.9 & 4.7 \\
Yinderitu profile 4 & 7.8 & 8.0 & 7.5 & 7.7 & 6.4 & 5.3 & 5.6 & 5.7 & 5.5 \\
\hline
\end{tabular}

Evaporite is usually scattered on the surface of these microreliefs, especially the leading edge of fan-shaped microrelief and tongue-shaped microrelief (Figure 2f). The ESEM and energy spectrum analysis results show that the forms of these evaporites are mainly a short columnar crystal (Figure 3a) and granular crystals (Figure $3 \mathrm{~b}$ ). The chemical components mainly consist of $\mathrm{CaO}, \mathrm{CO}_{2}$, and $\mathrm{SO}_{3}$ 
(Table 2). Therefore, the mineral composition of evaporites can be qualitatively determined as calcite $\left(\mathrm{CaCO}_{3}\right)$ and gypsum $\left(\mathrm{CaSO}_{4}\right)$. In addition, the chemical components of evaporite also include a small quantity of $\mathrm{MgO}, \mathrm{Na}_{2} \mathrm{O}, \mathrm{Cl}_{2} \mathrm{O}$, and $\mathrm{SiO}_{2}$, which indicates that there is a small quantity of dolomite, salt, and quartz in saline minerals. These minerals are common evaporite minerals in arid areas. Their appearance in microrelief surfaces signifies that the sand layer water has undergone long-term evaporation. In this desert, the precipitation is only $100 \mathrm{~mm}$ [18], and it is less likely for the enrichment of these evaporites caused by precipitation. As a result, the enrichment of evaporite should be related to the supply of the megadune vadose zone water to the microrelief sand layer water. The soluble salt content in aeolian sand is usually only $0.14 \%$ o to $1.32 \%$ [25], thus the salt enrichment on the surface of the microrelief indicates the long-term supply of the vadose zone water to microrelief sand layer water, which can also be proved by the hold time of the fan-shaped microrelief and tongue-shaped microrelief on the megadune slope.
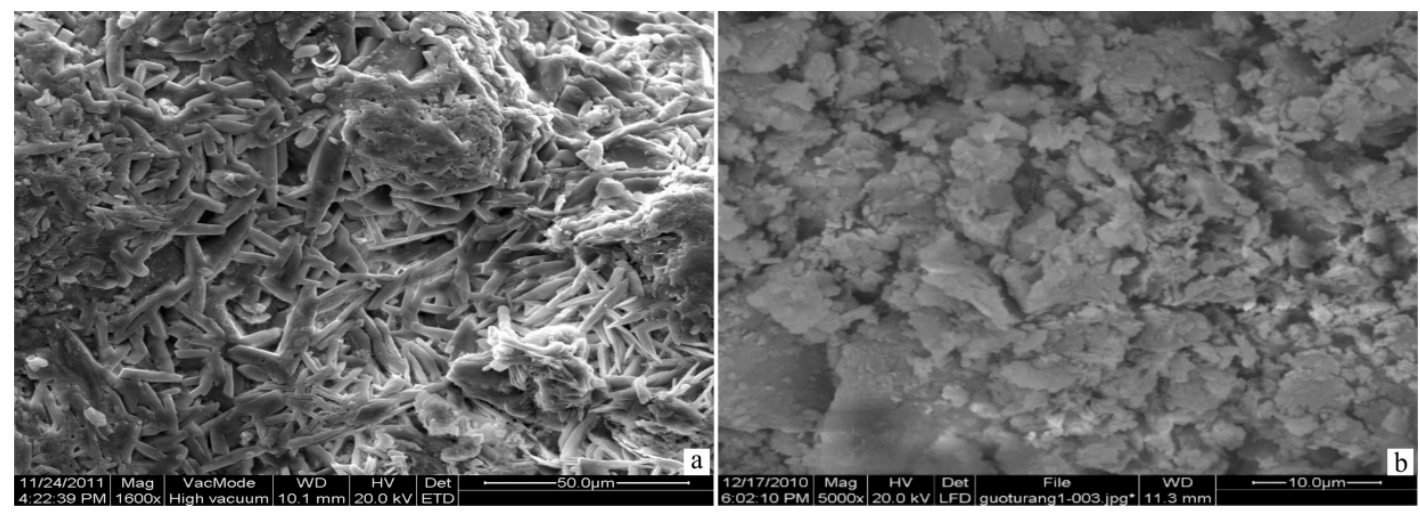

Figure 3. Short columnar gypsum crystal in the Yinderitu megadune of the Badain Jaran Desert (a) and granular calcite crystal in the Zhalate megadune of the Badain Jaran Desert (b).

Table 2. Chemical components of evaporite in the megadune of the Badain Jaran Desert (\%).

\begin{tabular}{cccccccccc}
\hline Sampling Site & No. & $\mathbf{C a O}$ & $\mathbf{C O}_{2}$ & $\mathbf{S O}_{3}$ & $\mathbf{M g O}$ & $\mathbf{N a}_{2} \mathbf{O}$ & $\mathbf{C l}_{2} \mathbf{O}$ & $\mathbf{A l}_{2} \mathbf{O}_{3}$ & $\mathbf{S i O}_{2}$ \\
\hline \multirow{2}{*}{ Yinderitu } & BJD-Y01 & 62.21 & 35.32 & & 1.45 & - & - & 1.03 & - \\
& BJD-Y02 & 52.01 & 44.65 & & 1.31 & - & - & - & 1.11 \\
\hline \multirow{3}{*}{ Zhalate } & BJD-Z01 & 36.95 & 0.51 & 51.66 & 5.27 & 5.27 & 2.06 & - & 2.61 \\
& BJD-Z02 & 52.86 & 44.68 & - & 1.33 & - & - & - & 1.13 \\
& BJD-Z03 & 32.45 & 0.50 & 52.97 & 6.12 & 6.12 & 0.95 & - & 4.67 \\
\hline
\end{tabular}

In particular, the leading edge differential wind erosion feature of a larger microrelief is significant. The coarse sand layer is more subject to wind erosion than the fine sand layer as the fine sand layer is hardened due to calcareous cementation (Figure 2f). Through observing the internal structure of the microrelief, it can be found that the internal fine sand layer color is darker than the coarse sand layer (Figure 2d,e). As the water holding capacity of fine sand layer is better than coarse sand layer, the color difference can be put down to the higher humidity of the fine sand layer than the coarse sand layer. Relevant researches indicate that soil water appeared to be transported through the apparently highly pervious and homogeneous sand along the dune slopes [17], which is greatly supported by the leading edge differential wind erosion feature of microrelief and fine sand layer calcareous cementation. The internal bedding of microrelief is thin, which is mostly on a mm scale. Only seldom bedding can reach centimeter scale. Therefore, it can be determined that the water from the megadune vadose zone migrates and recharges to the microrelief water along the dune micro-scale fine sand layer, during which, it features a multiple layer as it is controlled by a vertical sand layer structure. Based on the above analysis, the outcropping of megadune vadose zone water is the requirement for the appearance of the assemblage of the megadune microrelief and evaporites. 
The assemblage is the concrete evidence for precipitation to recharge the megadune and movement of megadune vadose zone water as preferential flow.

\subsection{Assemblage of Megadune Vegetation and Microrelief}

The assemblage of vegetation and microrelief in the megadune of the BJD features both a small scale (Figure $4 a, b$ ) and large scale (Figure $4 c, d$ ). These assemblages are distributed on the windward slope and leeward slope of the megadune and are usually distributed on the slope above the middle part of the megadune. The slope dip of vegetation and microrelief location falls between $24^{\circ}-30^{\circ}$, sometimes near $35^{\circ}$. The small-scale assemblage of vegetation and microrelief is usually composed of a small microrelief and vegetation patch. The scale of microrelief falls between $3-5 \mathrm{~m}^{2}$ and the vegetation patch usually appears on the upper and lower part of the microrelief. The scale of vegetation patch is usually small, falling between $3-20 \mathrm{~m}^{2}$. The vegetation composition type is usually Phragmites australis, Tamarix laxa, Calligonum alaschanicum, and Psammochloa villosa. The megadune P. australis and T. laxa patch are most typical with an area of only $3-10 \mathrm{~m}^{2}$ (Figure 4a). P. australis is usually distributed densely with a plant height of around $30 \mathrm{~cm}$ to $50 \mathrm{~cm}$, and the T. laxa are few in number, mostly single plant or multiple plants with a height of 1-2 $\mathrm{m}$ and a main trunk diameter of $3 \mathrm{~cm}$ to $5 \mathrm{~cm}$. The large-scale (or slope scale) assemblage of vegetation and microrelief usually consists of several different types of microrelief and vegetation band. The two present alternative distribution features on the megadune slope. The scale of the microrelief reaches nearly 100 square meters at times, which is related to the concentration of three basic forms of microrelief in Section 3.1. The vegetation band features large scale, large quantity, and type of vegetation without growth of P. australis and T. laxa.

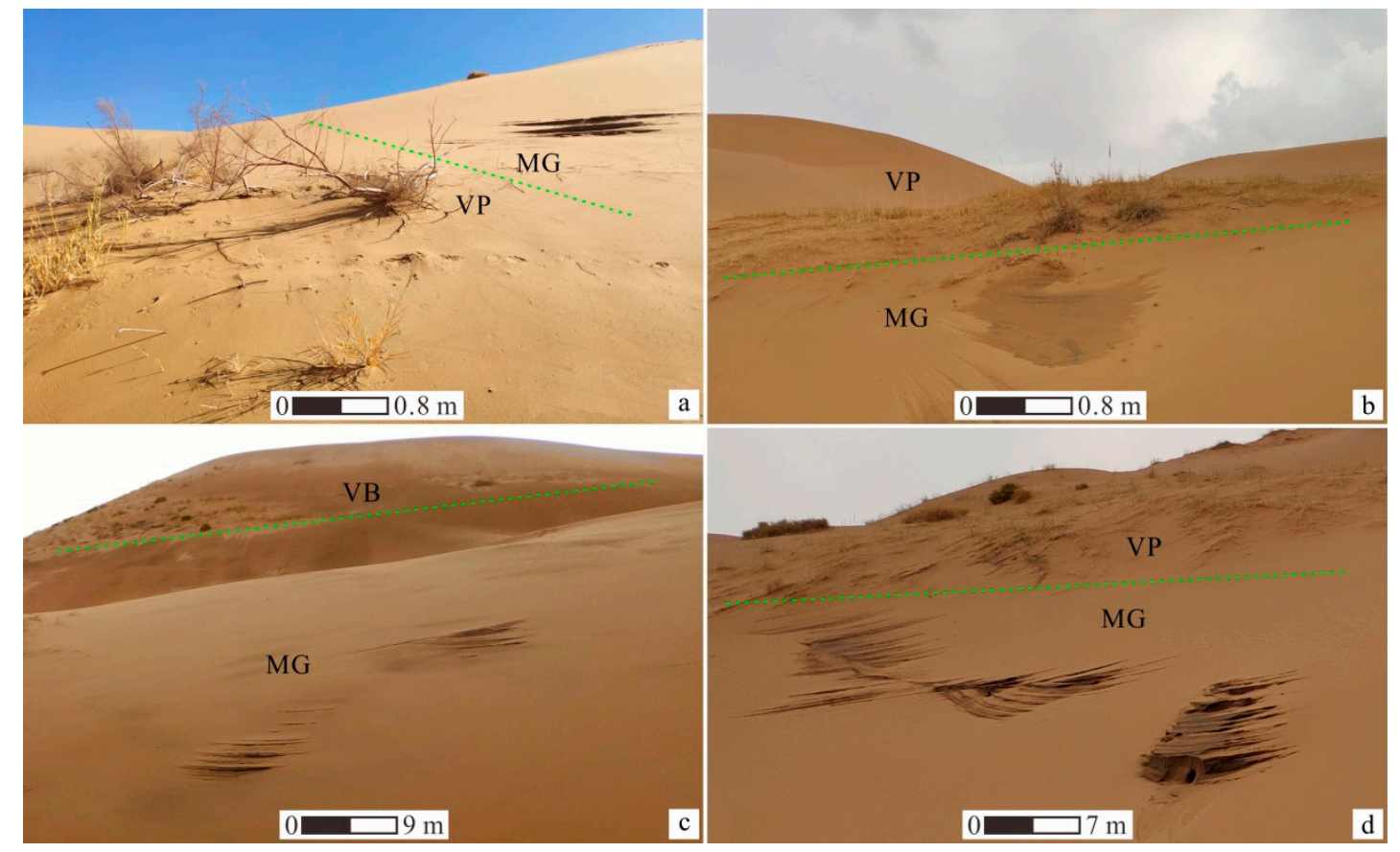

Figure 4. Small-scale $(\mathbf{a}, \mathbf{b})$ and large-scale $(\mathbf{c}, \mathbf{d})$ vegetation and microrelief assemblage: (a) is located in the Yinderitu megadune; (b-d) are located in the Zhalate megadune; (MG) refers to microrelief; (VP) vegetation patch constituted by Phragmites australis, Tamarix laxa, Calligonum alaschanicum, Psammochloa villosa and so on; (VB) refers to vegetation band constituted by Calligonum alaschanicum, Artemisia blepharolepis, Psammochloa villosa, and so on.

P. australis and T. laxa are typical xerophytic vegetation in the arid region, commonly seen in both sides of the river with shallow groundwater and the edge of irrigated farmland and other positions with good water conditions [26]. The megadune P. australis and T. laxa grow on the upper part of the 
megadune, which is at least 100 meters from groundwater. Apparently, the megadune groundwater, under the capillary action, cannot reach this height and maintain the growth of $P$. australis and T. laxa. The microrelief is related to the outcropping of the megadune vadose zone water associated with the vegetation of $P$. australis and T. laxa, which means that the megadune vadose zone water provides a critical water condition for the growth of vegetation of P. australis and T. laxa. The vegetation band is commonly seen in the fine-grain soil slope of an arid area, the growth of which is related to the surface runoff caused by precipitation. The precipitation is only around $100 \mathrm{~mm}$ in the desert [18], and the underlying sandy surface features strong infiltration. Surface runoff is not likely to exist in megadune slope. As a result, the water condition required for the development of megadune vegetation band can only be supplied by the vadose zone water of the megadune from the infiltration of precipitation instead of surface runoff. The small-scale assemblage of vegetation and microrelief is sufficient to prove that the movement of the megadune vadose zone water laterally leads to the development of vegetation. The dune's internal bedding structure is formed during the evolution of the dune [27-31], which is a direct result of grainfall, grainflow, and other sedimentary processes in megadune building dynamics [29]. The megadune in the desert underwent the evolution process of calcareous cementation-, aggradation-, re-calcareous cementation cycle [1], which determines the complexity of its internal bedding structure on spacial distribution. The assemblage of the megadune microrelief and evaporite and the assemblage of the small-scale vegetation and microrelief are results of the movement of the megadune vadose zone water along the sand layer micro-bedding. Therefore, it can be deduced that the assemblage of microrelief and vegetation of slope scale in the megadune represents the enrichment and runoff producing of the megadune vadose zone water due to the different bedding structure of the spatial position. Under comparison, the small-scale assemblage of vegetation and microrelief indicates the small-scale megadune hydrologic process, while the slope scale assemblage of vegetation and microrelief indicates the macro-scale megadune hydrologic process to a great extent. Therefore, the assemblage of vegetation and microrelief in megadunes of BJD also indicate the hydrologic process of supply of precipitation to the megadune and megadune vadose zone under contemporary climate conditions.

\subsection{Assemblage of Lakeside Runoff and Vegetation}

The off-shore area of lakes in the Badain Jaran Desert usually consists of the groundwater overflow zone and vegetation zone (Figure 5a). At the source of the groundwater overflow zone, many depression springs emerge. Below the source, there is a surface runoff erosion area. Above the source, there is a vegetation distribution zone. The major vegetation type in the vegetation zone includes Artemisia blepharolepis, Phragmites australis, Nitraria tangutorum bobr, Achnatherum splendens, and so on. Large shrub vegetation is seldom distributed and is densely grown with a coverage of $10 \%$ to $30 \%$. The depression spring is freshwater spring with an outcrop $0.3-0.5 \mathrm{~m}$ higher than the lake, sometimes reaching $4-5 \mathrm{~m}$. The erosion gully with a width and depth of $1-30 \mathrm{~cm}$ and $1-5 \mathrm{~cm}$ can be commonly found in the surface runoff erosion area and the surface runoff constituted by spring flows into the lake along the erosion gully. The total dissolved solids (TDS) of lake water is generally $100 \mathrm{~g} / \mathrm{L}$ and individually $400 \mathrm{~g} / \mathrm{L}$ in this desert $[9,11,32]$. This feature indicates that the development of the lakeside vegetation zone and the emergence of the groundwater overflow zone are not directly linked with lake water. According to the drilling survey on the lakeside vegetation zone in the desert, the lakeside stratigraphic sedimentary structure is an aeolian sand layer, peat layer, and lacustrine sedimentary layer from top to bottom (Figure $5 b$ ). In lakeside places, the phreatic water with a thickness of $20 \mathrm{~cm}$ to $40 \mathrm{~cm}$ is reserved to the bottom of the aeolian sand layer with a peat layer as a waterproof baseboard. As the distance of the drill hole and lake increases, the thickness of the phreatic water continues to increase [33]. The thickness of the peat layer is around $50 \mathrm{~cm}$ with an organic content reaching over $30 \%$, which is formed around 11 10cal ka BP [33]. The lacustrine sedimentary layer is composed of cyan-grey sub-clay with no obvious hydraulic conductivity and water yield property. 
It follows that the appearance of the lakeside groundwater overflow zone and the development of the vegetation zone are all related to the reserve and runoff of the phreatic water of this layer.

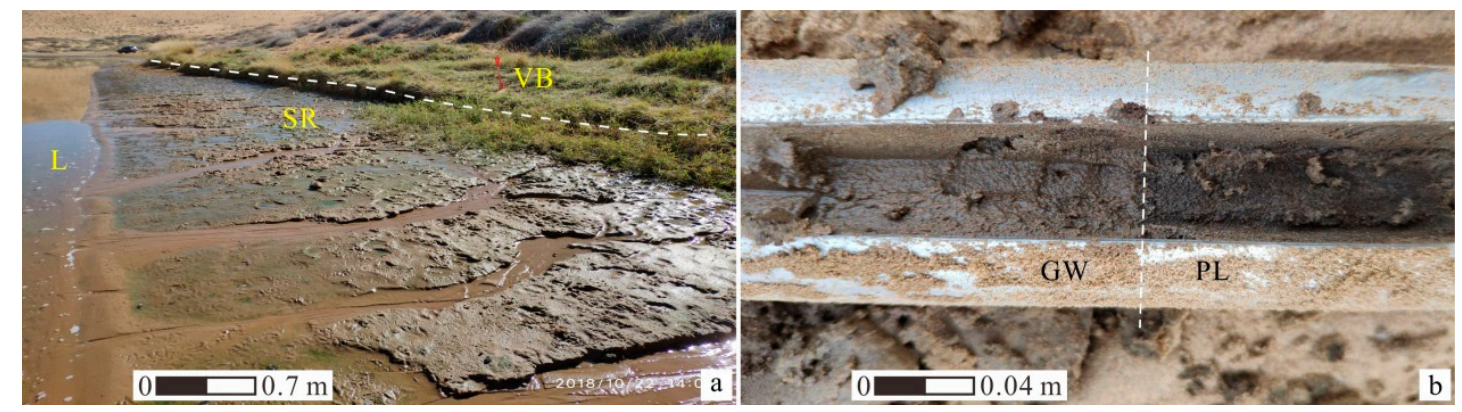

Figure 5. The assemblage of the Zhalate lakeside runoff and vegetation of the Badain Jaran Desert (a) and phreatic water occurrence condition (b): (L) represents lake; (SR) represents groundwater overflow zone; (VB) represents vegetation zone constituted by Artemisia blepharolepis, Phragmites australis, Nitraria tangutorum bobr, Achnatherum splendens, and so on; (GW) represents phreatic water layer; (PL) represents peat layer.

The depression spring is an important way in which the desert lake obtains supply. Research shows that the formation of the depression spring surrounding the desert lake is related to the overflow of deeper confined groundwater and the groundwater discharge base level raised by salt lake $[9,12]$. To a great extent, these interpretations are inconsistent with the reserve and runoff process of the lake's surrounding phreatic water. The in-depth groundwater TDS in the desert can reach $10 \mathrm{~g} / \mathrm{L}$ while the TDS of the depression spring is generally lower than $1 \mathrm{~g} / \mathrm{L}[9,11,32]$. Coupled with the hydrogeology features of the area surrounding the lake, the two are sufficient to prove that the supply source of phreatic water in areas surrounding lake should be atmospheric precipitation instead of deeper confined groundwater. Moreover, it is worth noting that the thickness of the phreatic water layer surrounding the lake is around $20 \mathrm{~cm}$ to $40 \mathrm{~cm}$. However, the annual fluctuating quantity of the lake water level is usually not more than $0.5 \mathrm{~m}$. This feature implies that the annual fluctuating quantity is closely related to the phreatic water surrounding the lake. Based on the above analysis, it is believed that the megadune water supplied by precipitation has been moved to the bottom of the megadune and supplied the lake water in this desert, and the supply of precipitation on the lake deserves attention. Therefore, the assemblage of lakeside runoff and vegetation in BJD provides strong evidence for precipitation to recharge groundwater and lake water through megadune infiltration.

\section{Discussion}

\subsection{The Conversion Process of Atmospheric Precipitation to Groundwater and Lake Water}

Previous studies have suggested that atmospheric precipitation is the recharge source of lake water in the BJD $[1,7,8]$, but there is little convincing evidence. The above assemblage of microrelief-evaporite-vegetation-runoff does indicate that the atmospheric precipitation in the area has become a recharge source of megadune water and lake water. Since the precipitation in the desert is very low, it is worth discussing whether it can recharge megadune water and lake water. Predecessors' studies have shown that it can constitute water recharge for deep sand layers as long as the single precipitation is greater than $15 \mathrm{~mm}$ in sandy deserts [16,34]. In recent years, the observation of precipitation shows that there is a certain single precipitation of more than $15 \mathrm{~mm}$ in the megadune-lake area of BJD. In 2008 and in the period of 2010-2012, the BJD witnessed at least five rainfalls with a precipitation of over $15 \mathrm{~mm}$, which were $23.9 \mathrm{~mm}$ on 30 July 2008 [21], $27.8 \mathrm{~mm}$ on 25 May 2010, $25.4 \mathrm{~mm}$ on 20 September 2010 [18], $17.8 \mathrm{~mm}$ on 17 August 2011 [18], and $43 \mathrm{~mm}$ on 20 July 2012 [20], respectively. According to the study of Yang et al. [16], the rainfall with a precipitation of over $25 \mathrm{~mm}$ in the past 50 years occurred 20 times in the Alxa Right Banner, close to the megadune lake area of 
the BJD. These observation results fully show that there is a strong precipitation process in the desert, which can provide an important water source for megadune water and groundwater.

The infiltration of soil moisture is the key link for the conversion of atmospheric precipitation to underground water in an arid area [16], which relates to water balance in arid areas. In most cases, it is believed that the aeolian sandy soil features strong homogeneity with water migrating in the form of piston flow. However, some researches indicate that aeolian sandy soil is able to produce preferential flow movement $[35,36]$. The assemblage of microrelief and evaporite and the assemblage of vegetation and microrelief in the megadunes of the BJD serve as strong evidence for the preferential flow movement of sandy vadose zone water. Through survey and analysis, the preferential flow movement of the sandy vadose zone water is subject to the internal bedding structure of the megadune. Ground-penetrating radar studies reveal patterns of water movement within the sand layer and indicate that the wetting fronts and preferential flow paths of sand layer water are controlled by stratigraphic features $[30,31]$. The dune internal structure referred to in past research was all medium- and large- scale. No micro-scale (namely mm scale) was mentioned largely. In fact, during the preferential flow movement of dune water, the internal structure of the micro-scale cannot be ignored. Berndtsson et al. [17] discovered the sand layer movement speed appeared to be about 2-3 m day $^{-1}$, while studying the relationship between dune water movement and temperature. However, this phenomenon is not further confirmed. Fortunately, the assemblage of microrelief and evaporite in the Badain Jaran megadune supports this discovery as the maintenance of microrelief sand layer water requires the fast supply of the vadose zone water under strong evaporation environment.

Based on the above analysis, the conversion process of atmospheric precipitation to groundwater and lake water indicated by the assemblage of the megadune microrelief and evaporite, the assemblage of megadune vegetation, and microrelief and the assemblage of lakeside runoff and vegetation can be explained as follows:

Atmospheric precipitation seeps and recharges the sand layer water which quickly moves in the form of preferential flow along the fine sand layer with high humidity. As the sand layer bedding of the micro-scale is densely distributed in the dune, the sand layer water presents the multi-layer feature during the preferential flow movement. As the water movement depth increases, the enrichment and runoff producing occurs as the water meets the dune bedding of middle- and large- scale. On the one hand, the enriched water will outcrop the megadune surface under proper conditions, which results in the assemblage of the megadune microrelief and evaporite and small-scale assemblage of the megadune microrelief and vegetation. On the other hand, the enriched water only reaches the surface of the megadune without outcropping, further constituting the water condition for vegetation band development. Specially, only a small part of the megadune vadose zone water can move to megadune's near-surface and consume through evapotranspiration. More water is still reserved in the deep vadose zone and moves downwards to supple the groundwater. In view of the difference in spacial distribution of megadune bedding and its relative water-resisting property, the macro-movement process of vadose zone water also presents multi-layer feature. The megadune water supplied by precipitation moves to the bottom of the megadune and is reserved above the water-resisting layer constituted by the peat layer and lacustrine sedimentary. Local phreatic water leads to the outcropping of depression spring in the form of runoff and further recharges lake.

\subsection{Lake Water Balance}

The lake water of the BJD is controlled by the evaporation and supply of groundwater, presenting a dynamic balance process of water yield input and output [9]. As the supply of surface runoff from regional precipitation on lakes is weak and no other direct supply from a surface water body exists, the supply source of lake water in this region only includes the following two ways, namely the direct supply of atmospheric precipitation and surrounding groundwater supply of lake. The annual evaporation capacity of lake water is around 1200-1550 $\mathrm{mm}$ [9] and the annual precipitation is around $100 \mathrm{~mm}$ in this desert [18]. Based on the above data, it can be calculated that the groundwater recharge 
per unit area of lakes in this area is about $1100-1460 \mathrm{~mm} / \mathrm{a}$. The total area of the megadune lake area is around 22,051.8 $\mathrm{km}^{2}$ [3], and the total area of the lake does not exceed $33 \mathrm{~km}^{2}[2,37]$, so that the area covered by the megadune is around 667 times the lake area. Assuming that the groundwater of unit area of megadune covered area can supply the lake in a balanced way. Through conversion, the groundwater of unit area of megadune covered area needs to supply around 1.6-2.2 $\mathrm{mm}$ of water to sustain annual lake evaporation. The water amount only occupies $1.6-2.2 \%$ of annual precipitation in the area. Currently, although the evaluation result of supply amount from precipitation on the megadune $[1,5,6,10,21]$ is subject to great uncertainty, it is of great reference value. Therefore, from water balance results and lakeside phreatic water occurrence condition, the role of precipitation in sustaining the long-term survival of the lake cannot be ignored in this desert.

\section{Conclusions}

The source of megadune water and lake water of the BJD has been controversial. In the field survey of the desert, three assemblages with an important indicative function of revealing water movement and lake water source were discovered, namely the assemblage of the megadune microrelief and evaporite, the assemblage of megadune vegetation and microrelief, and the assemblage of lakeside vegetation and runoff. Through the survey and analysis of microrelief sand layer water content, composition of evaporite minerals, and the hydrogeological feature of shallow strata surrounding the lake, the following conclusions were reached:

(1) The assemblage of the megadune microrelief and evaporite is the result of the outcropping of the megadune vadose zone water in the form of preferential flow for a long time. The differential wind erosion and fine sand layer calcareous cementation features in the leading edge of microrelief indicate that the water from megadune vadose zone migrates and recharges to the microrelief water along the megadune micro-scale fine sand layer, during which, it features a multiple layer as it is controlled by a vertical sand layer bedding structure;

(2) The appearance of the small-scale assemblage of megadune vegetation and microrelief indicates that the lateral movement of the megadune vadose zone water leads to vegetation development, and the slope scale assemblage of microrelief and vegetation indicates that the megadune vadose zone water supplied by precipitation presents multi-layer enrichment and runoff due to the bedding structure of the different spacial location;

(3) The appearance of the assemblage of lakeside runoff and vegetation is related to the phreatic water recharged by precipitation surrounding the lake, which indicates that the megadune water supplied by precipitation has been moved to the bottom of megadune to supply the lake water;

(4) Strong precipitation exists in the desert to provide an important supply for megadune water. The movement of megadune vadose zone water supplied by precipitation is subject to the control of bedding structure of different scale. The hydrological cycle approach is reflected as atmospheric precipitation-megadune vadose zone water-groundwater-lake water;

(5) The lake water balance results and lakeside phreatic water occurrence condition imply that the role played by precipitation in sustaining the lake cannot be ignored in this desert.

These results reveal the internal connection and occurrence mechanism among hydrological phenomena in the desert and provided reliable evidence for the precipitation supply to megadune water and lake water. The research work is of important scientific significance to the sandy desert hydrologic process in arid area and implies that the sandy desert precipitation is small but not negligible in the hydrological cycle components.

Author Contributions: Conceptualization, Y.M. and J.Z.; funding acquisition, Y.M.; investigation, Y.M., T.S., Z.J., Z.Z. and Z.G.; methodology, Y.M., T.S. and Z.J.; resources, Y.M., T.S., and Z.J.; validation, Y.M., J.Z., T.S. and Z.J.; writing-original draft preparation, Y.M. and J.Z.; writing—review and editing, Y.M., J.Z., T.S. and Z.J. 
Funding: This research was supported by the China Postdoctoral Science Foundation (2018M633438), the State Key Laboratory of Loess and Quaternary Geology, Institute of Earth Environment, Chinese Academy of Sciences (SKLLQG1713), and the "111" Program-Base construction of Innovation and Introducing Talents of Hydrology Ecology and Water Safety Discipline in Arid and Semi-Arid Regions (B08039).

Acknowledgments: The authors would like to thank Zhongdi Zhang at Shaanxi Normal University for assisting in the sample analysis, and thank all members who participated in the field survey in the Badain Jaran Desert.

Conflicts of Interest: The authors declare no conflict of interest.

\section{References}

1. Yang, X.P.; Ma, N.N.; Dong, J.F.; Zhu, B.Q.; Xu, B.; Ma, Z.B.; Liu, J.Q. Recharge to the Inter-Dune Lakes and Holocene Climatic Changes in the Badain Jaran Desert, Western China. Quarter. Res. 2010, 73, 10-19. [CrossRef]

2. Zhu, J.F.; Wang, N.A.; Li, Z.L.; Dong, C.Y.; Lu, Y.; Ma, N. RS-based monitoring seasonal changes of lake in Badain Jaran Desert. J. Lake Sc. 2011, 23, 657-664, (In Chinese with English abstract).

3. Zhu, J.F.; Wang, N.A.; Chen, H.B.; Dong, C.Y.; Zhang, H.A. Study on theboundary and the area of Badain Jaran Desert based on remote sensing imagery. Progr. Geogr. 2010, 23, 1087-1094, (In Chinese with English abstract).

4. Dong, Z.B.; Qian, G.Q.; Lv, P.; Hu, G.Y. Investigation of the sand sea with the tallest dunes on Earth: China's Badain Jaran Sand Sea. Earth Sci. Rev. 2013, 120, 20-39. [CrossRef]

5. Ma, J.Z.; Edmunds, W.M. Groundwater and lake evolution in the Badain Jaran Desert ecosystem, Inner Mongolia. Hydrogeol. J. 2006, 14, 1231-1243. [CrossRef]

6. Gates, J.B.; Edmunds, W.M.; Darling, W.G.; Ma, J.Z.; Pang, Z.H.; Young, A.A. Conceptual model of recharge to southeastern Badain Jaran Desert groundwater and lakes from environmental tracers. Appl. Geochem. 2008, 23, 3519-3534. [CrossRef]

7. Hofman, J. The lakes in the SE Part of Badain Jaran Desert, their limnology and geochemistry. Geowissenschaften 1996, 8, 275-278.

8. Ma, R.H.; Yang, G.S.; Duan, H.T.; Jiang, J.H.; Wang, S.M.; Feng, X.Z.; Li, A.N.; Kong, F.X.; Xue, B.; Wu, J.L.; et al. China's lakes at present: Number, area and spatial distribution. Sci. China Earth Sci. 2011, 54, 283-289. [CrossRef]

9. Wang, X.S.; Hu, X.N.; Jin, X.M.; Hou, L.Z.; Qian, R.Y.; Wang, L.D. Interactions between groundwater and lakes in Badain Jaran Desert. Earth Sci. Front. 2014, 21, 91-99, (In Chinese with English abstract).

10. Hou, L.Z.; Wang, X.-S.; Hu, B.X.; Shang, J.; Wan, L. Experimental and numerical investigations of soil water balance at the hinterland of the Badain Jaran Desert for groundwater recharge estimation. J. Hydrol. 2016, 540, 386-396. [CrossRef]

11. Shao, T.J.; Zhao, J.B.; Zhou, Q.; Dong, Z.B.; Ma, Y.D. Recharge sources and chemical composition types of groundwater and lake in the Badain Jaran Desert, northwestern China. J. Geograph. Sci. 2012, 22, 479-496. [CrossRef]

12. Chen, J.S.; Li, L.; Wang, J.Y.; Barry, D.A.; Sheng, X.F.; Gu, W.Z.; Zhao, X.; Chen, L. Groundwater maintains dune landscape. Nature 2004, 432, 459-460. [CrossRef] [PubMed]

13. Chen, J.S.; Zhao, X.; Sheng, X.F.; Dong, H.Z.; Rao, W.B.; Su, Z.G. Formation mechanisms of megadunes and lakes in the Badain Jaran Desert, Inner Mongolia. Chin. Sci. Bull. 2006, 51, 3026-3034. [CrossRef]

14. Dong, C.Y.; Wang, N.A.; Chen, J.S.; Li, Z.L.; Chen, H.B.; Chen, L.; Ma, N. New observational and experimental evidence for the recharge mechanism of the lake group in the Alxa Desert, north-central China. J. Arid Environ. 2016, 124, 48-61. [CrossRef]

15. Scanlon, B.R.; Keese, E.K.; Flint, A.L.; Flint, L.E.; Gaye, C.B.; Edmunds, W.M.; Simmers, I. Global synthesis of groundwater recharge in semiarid and arid regions. Hydrolog. Process. 2006, 20, 3335-3370. [CrossRef]

16. Yang, W.B.; Tang, J.N.; Liang, H.R.; Dang, H.Z.; Li, W. Deep soil water infiltration and its dynamic variation in the shifting sandy land of typical deserts in China. Sci. China Earth Sci. 2014, 57, 1816-1824. [CrossRef]

17. Berndtsson, R.; Nodomi, K.; Yasuda, H.; Persson, T.; Chen, H.; Jinno, K. Soil water and temperature patterns in an arid desert dune sand. J. Hydrol. 1996, 185, 221-240. [CrossRef] 
18. Wang, N.A.; Ma, N.; Chen, H.B.; Chen, X.L.; Dong, C.Y.; Zhang, Z.Y. A preliminary study of precipitation characteristic in the hinterland of Badain Jaran Desert. Adv. Water Sci. 2013, 24, 153-160, (In Chinese with English abstract).

19. Gu, W.Z.; Chen, J.S.; Wang, J.Y.; Zhao, X.; Xie, M.; Lu, J.J.; Seiler, K.P. Challenge from the appearance of vadose water within the surface layer of megadunes, Badain-Jaran dune desert, Inner Mongolia. Adv. Water Sci. 2004, 15, 695-699, (In Chinese with English abstract).

20. Ma, N.; Wang, N.A.; Zhao, L.Q.; Zhang, Z.Y.; Dong, C.Y.; Shen, S.P. Observation of mega-dune evaporation after various rain events in the hinterland of Badain Jaran Desert, China. Chin. Sci. Bull. 2014, 59, 162-170. [CrossRef]

21. Wen, J.; Su, Z.B.; Zhang, T.T.; Tian, H.; Zeng, Y.J.; Liu, R.; Kang, Y.; Velde, R. New evidence for the links between the local water cycle and the underground wet sand layer of a mega-dune in the Badain Jaran Desert, China. J. Arid Land 2014, 6, 371-377. [CrossRef]

22. Warner, T.T. Desert Meteorology; Cambridge University Press: Cambridge, UK, 2004; pp. 205-217.

23. Wang, T.J.; Istanbulluoglu, E.; Lenters, J.; Scott, D. On the role of groundwater and soil texture in the regional water balance: An investigation of the Nebraska Sand Hills, USA. Water Resour. Res. 2009, 45, 82-90. [CrossRef]

24. Zhao, J.B.; Shao, T.J.; Hou, Y.L.; Lv, X.H.; Dong, Z.B. Moisture content of sand layer and its origin in a megadune area in the Badain Jaran Desert. J. Nat. Resour. 2011, 26, 694-702, (In Chinese with English abstract).

25. Zhu, B.Q.; Yang, X.P. The origin and distribution of soluble salts in the sand seas of northern China. Geomorphology 2010, 123, 232-242. [CrossRef]

26. Maria, N.; Liu, W.G.; Huo, J.S.; Li, H.X.; Zhang, Y.; Liu, J.G.; Xv, Y. Ecological response and adaptation mechanism of Phragmites australis to changes in groundwater level. Acta Ecol. Sinica 2018, 38, 7488-7498.

27. Mckee, E.D. Structures of dunes at White Sands National Monument, New Mexico (and a comparison with structures of dunes from other selected areas). Sedimentology 1966, 7, 3-69. [CrossRef]

28. Bristow, C.S.; Bailey, S.D.; Lancaster, N. The sedimentary structure of linear sand dunes. Nature 2000, 406, 56-59. [CrossRef]

29. Vriend, N.M.; Hunt, M.L.; Clayton, R.W. Sedimentary structure of large sand dunes: examples from Dumont and Eureka dunes, California. Geophys. J. Int. 2012, 190, 981-992. [CrossRef]

30. Harari, Z. Ground-penetrating radar (GPR) for imaging stratigraphic features and groundwater in sand dunes. J. Appl. Geophys. 1996, 36, 43-52. [CrossRef]

31. Qian, R.Y.; Li, J.; Liu, L.B.; Zhao, Z. Internal structure of sand dunes in the Badain Jaran Desert revealed by GPR and its implications to inter-dune lake hydrology. In Proceedings of the IEEE 15th International Conference on Ground Penetrating Radar-GPR 2014, Brussels, Belgium, 30 June-4 July 2014; pp. 166-169.

32. Yang, X.P.; Williams, M.A.J. The ion chemistry of lakes and late Holocene desiccation in the Badain Jaran Desert, Inner Mongolia, China. Catena 2003, 51, 45-60. [CrossRef]

33. Wang, N.A.; Ning, K.; Li, Z.L.; Wang, Y.X.; Jia, P.; Ma, L. Holocene high lake-levels and pan-lake period on Badain Jaran Desert. Sci. China Earth Sci. 2016, 59, 1633-1641. [CrossRef]

34. Yuan, P.F.; Ding, G.D.; Wang, W.W. Characteristics of rain water in filtration and evaporation in Mu Us Sand Land. Sci. Soil Water Conserv. 2008, 6, 23-27, (In Chinese with English abstract).

35. Allaire, S.E.; Roulier, S.; Cessna, A.J. Quantifying preferential flow in soils: A review of different techniques. J. Hydrol. 2009, 378, 179-204. [CrossRef]

36. Rodný, M.; Lichner, L.; Karsten, S.; Ladislav, H. Depth-dependent heterogeneity of water flow in sandy soil under grass. Biologia 2015, 70, 1462-1467. [CrossRef]

37. Zhao, L.; Xiao, H.; Dong, Z.; Xiao, S.; Zhou, M.; Cheng, G.; Yin, L.; Yin, Z. Origins of groundwater inferred from isotopic patterns of the Badain Jaran Desert, northwestern China. Ground Water 2012, 50, 715-725. [CrossRef] [PubMed]

(C) 2019 by the authors. Licensee MDPI, Basel, Switzerland. This article is an open access article distributed under the terms and conditions of the Creative Commons Attribution (CC BY) license (http://creativecommons.org/licenses/by/4.0/). 